\title{
Sacrococcygeal Teratoma in Nigerian Children
}

\author{
A. OLUFEMI WILLIAMS, S. B. LAGUNDOYE, and M. A. BANKOLE \\ From The Departments of Pathology, Radiology, and Surgery, University of Ibadan, and \\ University College Hospital, Ibadan, Nigeria
}

\begin{abstract}
Williams, A. Olufemi, Lagundoye, S. B., and Bankole, M. A. (1970). Archives of Disease in Childhood, 45, 110 . Sacrococcygeal teratoma in Nigerian children. Two-thirds of all teratomas seen in 31 Nigerian children at Ibadan were situated in the sacrococcygeal region. About one-quarter of all the sacrococcygeal teratomas were malignant as shown on radiological and pathological examinations. The malignant tumours had papillary carcinomatous pattern, probably derived from the choroid plexus. The clinicopathological features of one patient with malignant change is described to illustrate the biological behaviour of this tumour. Malignancy in all the sacrococcygeal tumours appears to be associated with growth of the tumour into the pelvic cavity and metastasis initially to inguinal lymph nodes and later to distant sites. Inferior venacavogram can be of great value in defining the extent of the intrapelvic mass and the displacement of the genito-urinary organs, particularly when surgery is contemplated.
\end{abstract}

Sacrococcygeal teratomas occur almost exclusively in early life and there are several reported cases including an ancient record on a cuneiform tablet of Babylonian origin about 2000 B.C. (Ballantyne, 1894). There are very few reports of this tumour in Africa where teratogenic tumours are not uncommon (Williams, 1969). This paper deals primarily with 21 histologically proven cases of sacrococcygeal teratomas in Nigerian children. The specimens were either derived from cases seen in this hospital, or were sent to the Department of Pathology for pathological diagnosis over a period of nine years, 1960-68. A detailed clinicopathological case report of a 1-year-old child, who developed malignant change in a sacrococcygeal teratoma, is described to illustrate some of the unusual features met in this type of tumour. Teratomas of other sites seen in Nigerian children during the same period are also reviewed.

\section{Case Report}

A 16-day-old female baby, born at term, first presented with a very large soft, cystic, pendulous mass of the left buttock, with a circumference of about $30 \mathrm{~cm}$. No neurological deficit was elicited and radiography showed no involvement of the underlying bone. The tumour was excised at another hospital and sent to the Department of Pathology for histological examination. It consisted of a $323 \mathrm{~g}$. cystic mass with an overlying

Received 13 May 1969. piece of skin $14 \times 9 \mathrm{~cm}$. Cut surface showed multiple cystic cavities, $0 \cdot 3-2 \mathrm{~cm}$. in diameter, and a few solid $\vec{\varphi}$ yellowish areas. The cysts contained mucoid and sebaceous material and were separated from one anothe. by fibrous bands of varying width. There were als a few focal areas of calcification. Histologicall. tissues were found to arise from the three germ layerssquamous epithelium, neuroglial fibres, striated and smooth muscle, cartilage, bone, intestinal and respiratory types of epithelium, and there were foreign body giant cells reacting to lipoid material. None of these structures showed evidence of malignancy. The post-operative period was uneventful and the child was discharged.

Seven months later, there was recurrence of the tumour with an exuberant scar and the child was referred to the University College Hospital, Ibadan. Examination showed a soft, rather indefinite mass over the sacrococcygeal area, a little to the left of the midline. Investigations included $x$-rays of the lumbosacral spine and chest, intravenous pyelogram, and inferior venacavogram, and electromyography of the gluteal and thigh muscles.

The sacrum appeared normal but no coccygeal 을. segments were seen. Intravenous pyelogram showed $\bar{N}$ that both kidneys excreted the dye and the pelvicalyceal $\odot$ systems and bladder were normal. Chest $x$-ray $\mathrm{O}$ showed a segmental opacity at the left lung which was $N$ suggestive of atelectasis or pneumonia. A repeat $\sigma$ chest $x$-ray two weeks later revealed a large, round opacity at the left base posteriorly consistent with a tumour deposit (Fig.). An inferior venacavogram was $\mathbb{E}$ carried out at 1 year of age by injecting $15 \mathrm{ml}$. of sodium 
ditrizoate in $45 \%$ (Hypaque) into the left saphenous vein above the ankle. This revealed a round mass completely filling the pelvic cavity and displacing the pelvic veins around it (Fig.). The left common iliac vein was compressed but not occluded by the mass, and there was reflux of contrast into the right common iliac vein. Several collateral veins were visualized in the pelvis and perineum, some of which cross the midline to empty into the right femoral and external iliac veins (Fig.). The inferior vena cava was, however, normally

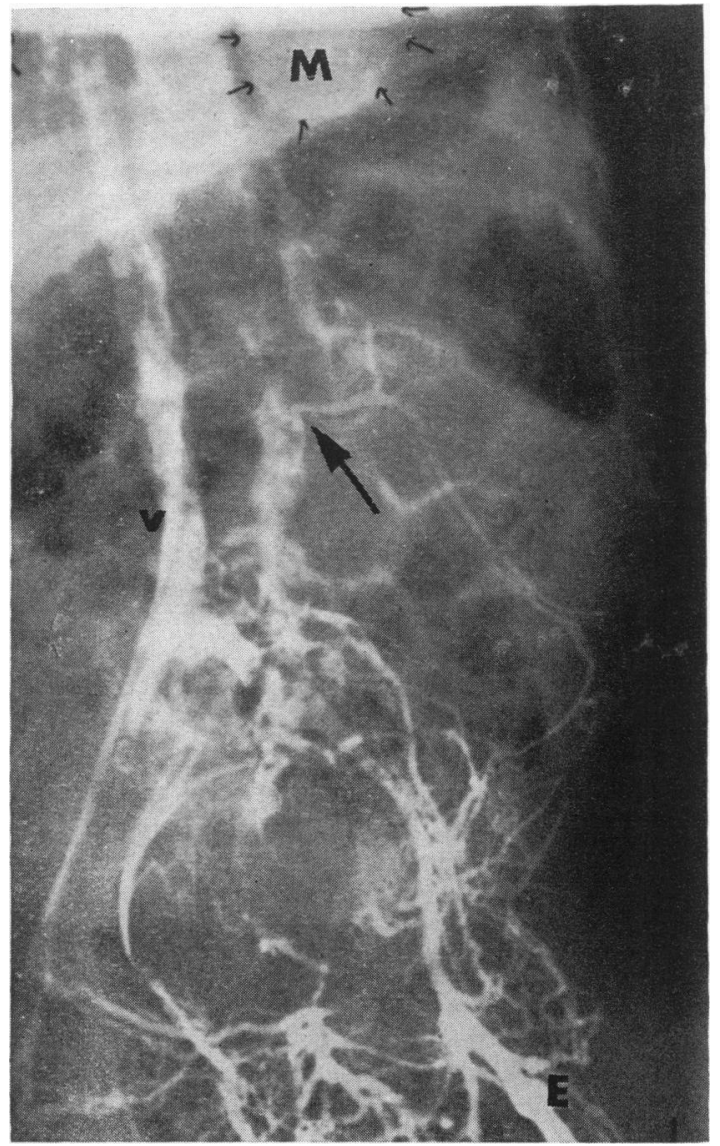

FIG.-Inferior venacavogram showing a round mass filling the pelvic cavity and compressing the common iliac veins. Several collateral vessels are seen and one pair links the left pubic area to the hemiazygos system via the first lumbar veins (arrow). $M=$ Metastatic tumour deposit in posterior base of lung. $V=$ Inferior vena cava. $E=$ External iliac vein.

situated. 20 minutes after the injection of contrast medium, an abdominal film showed no excretion of the contrast by the right kidney, suggestive of complete occlusion of the right ureter. The left pelvicalyceal system and upper ureter were slightly dilated and the lower end of the ureter was markedly displaced upwards and to the right pelvic wall. The bladder was shown to have been lifted upward and out of the pelvic cavity by the intrapelvic extension of the sacrococcygeal tumour. Electromyography of gluteal and thigh muscles was normal.

When the child was 1 year old, the mass was about $23 \mathrm{~cm}$. in its greatest diameter and was situated over the left gluteal region with obvious muscle wasting and weakness of the leg. The overlying skin was tightly stretched and a few shotty lymph nodes were felt in the inguinal regions. She could neither sit nor lie down. The tumour mass was excised, and postoperatively, actinomycin D, $15 \mu \mathrm{g}$. $/ \mathrm{kg}$. body weight, was given for 7 days. A mass became evident in the left groin which was continuous with the intrapelvic mass, and this continued to enlarge; she gradually deteriorated and died one month after the second surgical operation.

The recurrent tumour was a large, soft mass weighing $1050 \mathrm{~g}$., measuring $19 \times 14 \times 11 \mathrm{~cm}$. There was a $7 \mathrm{~cm}$. long linear healed scar in the centre of the overlying skin. The cut surface revealed a predominantly solid tumour mass with areas of haemorrhage, necrosis, and mucoid degeneration. Histologically, there was a teratoma with tissues derived from the various germ layers, similar in appearance to the previous specimen. In addition there were solid cellular areas composed of malignant papillary structures consistent with 'papillary carcinoma-like' areas described occasionally in malignant teratomas (Fletcher and Waring, 1900; Pandalai, Forsyth, and Stewart, 1924; Stewart, Alter, and Craig, 1930; Lisco, 1942).

Necropsy. The main finding was in the pelvis and metastatic tumour deposits were seen in the lungs, kidneys, and inguinal nodes. In the pelvis, there was a large retroperitoneal cystic mass with a moderately thickened fibrous wall which contained $315 \mathrm{~g}$. necrotic haemorrhagic tumour. It was soft and fragile and flowed out in a semi-solid state. The cystic mass compressed the pelvic colon and rectum, displacing the former laterally and the latter posteriorly. Coccygeal segments were absent and there was a connexion between the pelvic mass and the excised portion of the tumour externally. The bladder was slightly distended and the urethra was elongated and dilated. The bladder was raised and displaced out of the pelvis by a mass on which it was lying superiorly and laterally. The uterus, ovaries, and tubes were also displaced likewise and were lying posteriorly to the bladder. There were multiple tumour nodules in the kidneys measuring 4-15 $\mathrm{mm}$. in diameter, and multiple tumour deposits in the lungs, the largest being in the posterior basal lobe of the left lung, measuring $4 \times 4 \mathrm{~cm}$. (Fig.), and also in the subcutaneous tissue.

\section{Comment}

Teratomas in infancy may present in a variety of sites of which the sacrococcygeal region is the 
commonest. The predilection for this site may be due to the fact that the greatest concentration of primordial cells in a neonate occurs at the primitive knot near the coccyx. In this series of 31 cases, all the patients were under the age of 2 years; 5 were noticed at or before birth, and 9 were noticed within 2 weeks of birth. The site distribution of all cases of teratoma seen in early life is summarized in Table I: 21 cases $(66 \%)$ were in the sacro-

TABLE

Site Distribution of Teratomas in Nigerian Children

\begin{tabular}{|c|c|c|c|c|}
\hline Site & & Males & Females & Total \\
\hline 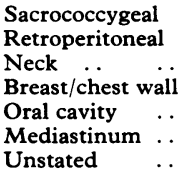 & $\begin{array}{l}\cdots \\
\cdots \\
\cdots \\
\cdots \\
\cdots \\
\cdots \\
\cdots\end{array}$ & $\begin{array}{l}6 \\
2 \\
0 \\
1 \\
0 \\
0 \\
0\end{array}$ & $\begin{array}{r}15 \\
0 \\
3 \\
0 \\
2 \\
1 \\
1\end{array}$ & $\begin{array}{r}21 \\
2 \\
3 \\
1 \\
2 \\
1 \\
1\end{array}$ \\
\hline Total & & 9 & 22 & 31 \\
\hline
\end{tabular}

coccygeal region. There were 15 females and 6 males consistent with a preponderance of females reported in other series (Hansmann and Berne, 1932; Williams, 1935).

Of the 21 cases of sacrococcygeal teratoma, 5 $(25 \%)$ were malignant using histological criteria. The observed frequency of malignant transformation in this series is high and cannot be regarded as a true incidence of malignancy in sacrococcygeal teratomas. One reason for this high frequency may be that tumours which recurred after surgery in other hospitals were referred to this centre. From the series, it appears that when teratomas recur after initial ablation, malignant transformation should be strongly suspected. Three were only evident histologically on examination of the recurrent tumours and two patients had metastases to inguinal nodes, lungs, and vertebrae on radiological and necropsy examinations. 4 of the 5 malignant cases were females and 1 was male; their ages at presentation were between 1 and 2 years. The malignant histological element in 4 cases was papillary, and in 1 case cystic with papillary areas. It is likely that the choroid plexus is the tissue of origin for malignancy, though an ependymal origin cannot be firmly excluded. In 1 case there was a highly cellular spindle-shaped component which was primitive neuroglial tissue.

All the 5 patients with malignant change died within a year of diagnosis, but necropsy was carried out only on the patient described. It appears that some of these tumours behaved initially as benign lesions and later became malignant, though it could be argued that malignant foci were missegू in original specimens. The predisposing factors. for malignancy were not evident. The majorit of the primary lesions occurred from birth and under the age of 1 year, while the malignant recurrent tumour seemed to present after the first year of life. The operative treatment for this tumour: has been well described (Gross, Clatworthy, ang Meeker, 1951); complete ablation is necessare to prevent recurrences. It is conceivable that the tumour was not completely removed initially in our patient, and that this predisposed to rapid regeneration and subsequent malignancy.

The clinical features and biological behaviou of the case reported here duplicated those of Lisco's cases (1942) in which the tumours grex rapidly and metastasized to inguinal nodes and viscera.

Most of the tumours were circumscribed and contained a great variety of well-differentiate $\Phi$ tissues. The unusual histological feature commog to all the malignant teratomas was the papillary carcinoma-like growth which has been suggested to be derived from the choroid plexus (Willis, 1962\%

Recent review of material from New Orlean in America, a city of about the same population as Ibadan, revealed 13 cases of sacrococcygeat teratomas in 16 years (Levy and Linder, 1960\% When compared with our experience of 21 ç्ठses in 9 years, sacrococcygeal teratomas seem to $\$$ more common in Ibadan.

When teratomas of other sites are compare with those of the sacrococcygeal area, they are nof as common (Table), and malignant change has nof been seen. It is significant that malignant change did not occur in teratomas arising in areas devoid of choroid plexus though not all tumours arise: from choroid plexus tissue.

In the remaining 16 non-malignant sacrococcyged teratomas examined, different types of tissues, including some unusual varieties, were encountere such as pancreatic, renal, and neuroglial tissues. thyroid and retinal epithelium, respiratory ang intestinal epithelium, and lobules of liver tissue Psammoma bodies were not uncommon, and choroid plexus was seen in nearly all the cases sacrococcygeal teratomas. Other sites involve by teratomas included neck, chest wall, mediasos tinum, retroperitoneum, and oral cavity (Table The teratomas of the neck region were usuallo very large and were found in female childrent In one of the patients, it was considered that the tumour arose from the thyroid gland, while it was not possible to decide the tissue of origin in the other two cases (Bale, 1950; Keynes, 1959: Silber 
man and Mendelson, 1960). The patient with thyroid teratoma was operated upon and followed up for about one year, and no recurrence was observed. The teratoma of the chest wall was in a 7-month male child; a two-year follow-up after surgical removal showed no evidence of recurrence. The oral teratomas were associated with abnormal fetuses, with death soon after birth.

Retroperitoneal teratomas were in slightly older children, the youngest being 8 months; they reached very large sizes and were only diagnosed at laparotomy. They presented with indefinite abdominal masses and abdominal distension. There was an anterior mediastinal teratoma which was indistinguishable clinically and on gross examination from a thymic neoplasm. The tissue of origin could not be determined but there was considerable atrophy of remaining thymic tissue. The histological appearances of these teratomas are similar to those seen in the sacrococcygeal region, with the exceptions that they possess less nervous tissue and have no choroid plexus. Malignant change was not seen in any of the tumours outside the presacral or sacrococcygeal region.

We wish to thank the staff of the Medical Illustration Unit of the University of Ibadan for the photograph.

\section{REFERENCES}

Bale, G. F. (1950). Teratoma of the neck in the region of the thyroid gland. A review of the literature and report of four cases. American fournal of Pathology, 26, 565.
Ballantyne, J. W. (1894). The teratological records of Chaldea. Teratologia, 127.

Fletcher, H. M., and Waring, H. J. (1900). Two cases of congenital sacro-coccygeal tumour. Transactions of the Pathological Society of London, 51, 226, cited by R. A. Willis (1962) q.v. in The Pathology of the Tumours of Children, p. 82.

Gross, R. E., Clatworthy, H. W., Jr., and Meeker, I. A., Jr. (1951). Sacrococcygeal teratomas in infants and children. Surgery, Gynecology and Obstetrics, 92, 341 .

Hansmann, G. H., and Berne, C. J. (1932). Sacrococcygeal teratomas. Archives of Surgery, 25, 1090.

Keynes, W. N. (1959). Teratoma of the neck in relation to the thyroid gland. British fournal of Surgery, 46, 466.

Levy, J. L., Jr., and Linder, L. H. (1968). Sacrococcygeal teratomas in infants. American fournal of Surgery, 116, 822.

Lisco, H. (1942). Malignant tumors developing in sacrococcygeal teratomata. Annals of Surgery, 115, 378.

Pandalai, K. G., Forsyth, W. L., and Stewart, M. J. (1924). Sacrococcygeal teratoma containing gliomatous, (?) chordomatous and ependymal-carcinomatous tissue. Fournal of Pathology, 27, 139, cited by R. A. Willis (1962) q.v. in The Pathology of the Tumours of Children, p. 82.

Silberman, R., and Mendelson, I. R. (1960). Teratoma of the neck. Report of two cases and review of the literature. Archives of Disease in Childhood, 35, 159.

Stewart, J. D., Alter, N. M., and Craig, J. D. (1930). Sacrococcygeal teratomata with malignant degeneration in childhood. Surgery, Gynecology and Obstetrics, 50, 85.

Williams, A. O. (1969). Teratomata in Nigerians. African fournal of Medical Science. In the press.

Williams, W. R. (1935). Teratoid Tumours. With Special Reference to the Sacro-coccygeal Group. E. J. Burrows, Cheltenham and London, cited by R. A. Willis (1960), in Pathology of Tumours, 3rd ed. p. 956. Butterworths, London.

Willis, R. A. (1962). The Pathology of the Tumours of Children. p. 82. Oliver and Boyd, Edinburgh and London.

Correspondence to Dr. A. O. Williams, Department of Pathology, University College Hospital, Ibadan, Nigeria. 